Article

\title{
Engaging with the Beyond-Diffracting Conceptions of T-Learning
}

\author{
Stefan Bengtsson
}

SWEDESD, Uppsala University, 75105 Uppsala, Sweden; stefan.bengtsson@swedesd.uu.se

Received: 28 January 2019; Accepted: 14 June 2019; Published: 21 June 2019

check for updates

\begin{abstract}
This paper develops a theory of transgressive learning (t-learning) as it was experimented with in the International Science Council t-learning network. The method applied is a diffractive reading of conceptions of transgression in academic publications emerging from different cases. The results show that there can be no definite conduct to or understanding of transgression, as transgression itself entails a subversion of rules, contexts, and borders. Instead, the results document several overarching categorical positions and axiomatic understandings of transgression that emerge from the background of context-specific wicked sustainability issues. Transgressive learning can be understood as a set of contextually diverse techniques and practices that attempt to bring about change through and in learning. Transgressive learning can result in experiential learning excesses where the excess is the very source of difference and makes change possible. The diversity of conceptions of transgressive learning open up new entry points for engaging with sustainability-oriented learning and education that is open to change rather than to reproducing unsustainable social structures and dynamics.
\end{abstract}

Keywords: transgression; learning; hegemony; diffraction; education; sustainability

\section{Introduction}

Increasingly, politicians and researchers have concluded that radical and rapid action is needed to address environmental concerns, with climate change emerging as a major threat to the existence of humanity. In addition, given that current economic and political systems have proven themselves to be inadequately prepared to meet these challenges, this lack of change indicates the resilience of unsustainable modes of social and economic production and reproduction [1]. Therefore, there is an increasing and urgent call for social transition and transformation towards greater sustainability. For example, the United Nations' Sustainable Development Goals (SDG) identify education as a crucial means for achieving social transformation, and the United Nations Framework Convention on Climate Change sees education as crucial for addressing climate change [2].

The Transformations to Sustainability (T2S) programme developed by the International Science Council (ISC) (former International Social Science Council) is one effort to identify how to achieve greater sustainability through innovative and collaborative research. The t-learning, Transformative Knowledge Network, consists of a virtual, interconnected research school. The research schools focus on nine national case studies, including Sweden, Malawi, Zimbabwe, India, Netherlands, Vietnam, Ethiopia, Colombia, and South Africa. Research conducted in the t-learning research school is among other activities to primarily investigate t-learning processes and develop methodologies to inform socio-ecological science research and practice. The outputs of this co-engaged research is to shape practice, theory and methodology for t-learning. This paper aims to contribute to the project by aiming at further developing the theory of t-learning.

While acknowledging the importance of education for promoting sustainable development, T2S's focus on transgressive and transformative learning breaks with the reproductive and linear notion 
of education embraced by SDG 4. Transgressive and transformative learning, as it is argued within the t-learning network, calls for a more radical and disruptive learning that moves beyond social reproduction. Within education research, T2S has funded a t-learning network that attempts to understand how transformative and transgressive learning (t-learning) processes emerge, what they look like, and how they can contribute to transformations to sustainability. While the initial effort was to focus on both transformative and transgressive learning, the project participants came to refocus on the concept of transgressive learning as a more radical form of learning. The radical aspect relates to the focus on discontinuity and breaking with continuity in learning, rather than the assumed accumulative and continuous aspects of learning as highlighted in transformative learning. Transformative learning was originally introduced by Mezirow, and focuses on the role of critical cognitive reflection and self-reflection as means of transformations of perspectives [3-5]. Transformative learning can, as pointed out by Illeris, be seen to rearticulate cognitivist learning theories and to expand on the process of accommodation by introducing the notion of transformation [6]. Transformation in this sense relates the transformation of already existent perspectives in reasoning. Accordingly, rather than engaging in a radical disengagement and disruption of existing systems of practices and norm systems, transformative learning is focused on changes to that which remains continuous [5]. Transgression was in the project conceived to provide an alternative entry point, as its primary focus is on initially breaking with that which is to be retained, as it questions and abandons norm foundations to explore radically different ways of being $[7,8]$. Transgressive learning with this radical break with continuity is an emergent concept in learning, where the t-learning network came to experiment with it as a guiding concept, as well as to develop practical pedagogies and techniques that at least in the initial stages of the learning process aim to disrupt, disengage and momentarily leave behind held perspectives and assumptions. The focus was to explore means and practices that can lead to such a break and less on the development of a learning theory of transgression.

This paper aims to pick up the initial theoretical work that has been accompanying the exploration of practices and techniques by exploring further what a theory of transgressive learning might consist of. Given the limited scope of the paper, the focus will be on the conception of transgressive learning per se and only to a limited extent on how this conception relates to existing learning theories. In this paper, I try to specify conceptually and theoretically outline how transgressive learning is a distinct learning concept that is not subsumed in the concept of transformative learning. Building on the seminal work of Lotz-Sisitka et al. and Macintyre et al., this paper aims to further develop the theoretical contributions of academic publications that examine transgressive learning which emerged in the t-learning network [7-11].

Consequently, this paper engages a theoretical reduction of the conception of transgressive learning as documented in the scientific publications of the ISC $\mathrm{t}$-learning network. By theoretical reduction, I refer to an attempt that resembles the process of reduction in cooking. This theoretical reduction acknowledges the variety and differences of tastes of different conceptions of $t$-learning as they emerge in the specific cases. At the same time, it aims to condense them into a reduced substance, where nuances remain distinct, yet interact. The reduction does so by avoiding to subdue or eradicate differences in the theoretical conceptions or integrate them into an assumed general theory of transgressive learning. Instead, it sees transgressive learning as a shared concept (substance) that attains meaning differently according to contextual engagements with transgressive learning in the different cases. The way it is understood as to attain meaning differently is theoretically developed further below in the explanation of diffractive reading as a method.

\section{Methodology and Materials}

The theoretical reduction uses diffractive reading of publications produced in the context of the project as a method $[12,13]$. (See Appendix A for overview of the texts reviewed). All texts quoted in Section 3 (Results) consist of project outputs. As conceived by Barad, diffractive reading reduces the influence of binary positions that reproduce hierarchies and power structures in texts [12]. I here 
utilize Barad's notion of diffraction as "the practice of reading insights through one another while paying attention to patterns of difference" [14]. My understanding of diffraction however differs from Barad's conception, which is modified by not only looking at patterns of difference, but also by looking at patterns of similarities. In the analysis of patterns of similarities, I am particularly interested in how seemingly similar categories are utilised to structure these patterns of difference.

I see my diffractive reading as purpose driven, that is, it aims to initiate the development of a context sensitive theory of transgressive learning that pays attention to the emergence of patterns of similarities and differences in my reading of the above-mentioned texts. The purpose to that extent shapes the emergence of patterns, yet, aims to a certain extent to remain sensitive to the contextuality of the meaning of these texts and conceptions of transgressive learning. The purpose of the reading is to identify patterns of similarities and differences in the conception of transgressive learning in the different publications emerging out of the t-learning project. The identification of patterns was conducted as part of a familiarization with conceptions by the way of diffractive reading. The articulation of these patterns was continuously nuanced and re-structured through reengagement with the texts. Based on this process of familiarization, I came to structure the presentation of conceptions of transgressive learning in the following matter. First, all papers can be seen to make assumptions on how they contribute to or are based in a notion of learning that relates to the t-learning project and its objectives. These assumptions about learning and how it feeds into the project are presented in Section 3.1.

Texts cited in this section represent for the most part cumulative publications that feed into the conception of transgressive learning without being explicitly grounded in and speaking to contexts. My reading is to tease out and elucidate assumptions about how learning relates to transgression. Based on my reading, I differentiate between two general forms of transgressive learning, rational and emotional learning that emerged as patterns of differences in these cumulative publications. In order to tease out these patterns of differences, I was forced to nuance the descriptions by reading additional texts that also partially covered more context specific conceptions as covered under Section 3.2.

To elaborate the purpose of the reading against the background of the presented results, my ambition with the analysis is not to engage in a form of violence on the vibrancy and richness of the different cases and outcomes, but to allow for this vibrancy and richness of the conceptions of transgressive learning by relating and highlighting diffracting traces among conceptions without valuing and fully eradicating differences. Differences in transgressive learning are not treated as fully autonomous, but as diffracted; that is, they are entangled with other texts as well as experiences of here, there, and now $[13,15]$. My ontologically-assumed entanglement provides a foundation for analysis and theoretical reduction. I use reduction instead of comparison to highlight that nuances are not to be excised as in a comparison, but rather that entanglement allows differences to move closer, to be related, without reducing that which is related to a determinable unity. Therefore, this paper does not make universal claims about what transgressive learning is or how transgressive learning is conceived in the actual local cases, but rather this paper outlines certain similarities and differences as identified among the texts as part of the process of reading.

Hence, the reading was guided and limited by the objective to identify similarities and differences, as they might both contribute to the project of developing a theory of transgressive learning. Consequently, my diffractive reading aims to elucidate what these conceptions of transgressive learning, in the situatedness of specific cases, might mean for the future development of a theory of transgressive learning. As Barad might put it, I aim to read insights through another, rather than against another [12]. I aim to bring contextually different conceptions together with the purpose of opening up future dialogue and connections among meanings. Accordingly, I do not put a specific value to the conceptions of transgressive learning put forward but aim to bring them together to create a dialogue among texts in order to initiate the development of a theory of transgressive learning. For my understanding of the significance of the analysed texts this means that a text, in its specificity and difference, stands in for transgressive learning as a whole. These different analysed texts are treated as 
synecdoche, where they are interpreted as not fully determining the whole, nor to be determined by it. They are purposefully brought together by the project as well as my reading.

This overall method described above also influences the expected outcome of the diffractive reading, which is to engage in the theoretical reduction of transgressive learning. As I argue, transgressive learning requires a fluid acknowledgement of boundaries in theory as they are approached and even created in situ and in experience. Accordingly, transgressive learning cannot theoretically be reduced to a singular position within a universal context. The locus of the potential of transgressive learning resides in the interplay between an elusive border and different productive ways of re-establishing that border. Every text has cracks that allow outside influences to seep in, entangling the text with other texts, which are often not even remembered [15]. In the case of this analysis, this means that the contextuality of the cases can be seen as traces to other texts and practices outside the particular conception of transgressive learning within the texts. To put it differently, the outside and context can be seen to be internal to the conceptions of transgressive learning, in the sense that its meanings is dependent on traces to other signifying practices in the past that are not fully present [16]. The theoretical reduction brings through this diffractive reading certain traces closer, without claiming to fully bring into presence and to make present all the traces that a text and the meaning of transgressive learning hinges upon.

Consequently, the theoretical reduction to be accomplished as part of the diffractive reading acknowledges that the God is in the details, the situational experiential engagement that the cases document, yet do not claim to not fully account for these details. Instead it is focused, as the theoretical reduction aims at engaging with the devil whom sits in the categories that are brought into play once boundaries are paradoxically established as the result of transgressing the boundaries. I address in this recourse to the devil who sits in the categories of Harman's critique of Barad's notion of diffraction, and aim to combine an analysis of patterns of differences with an analysis of patterns of similarities that I interpret as being associated with categories brought into play to give meaning [17]. It is with this additional focus on identifying categories that make a difference and at the same time provide the possibility for similar positions to emerge, that the diffractive reading in this paper differs significantly from Barad's conception.

Categories are in my understanding a priori assumptions about how the world appears, that are not explicitly stated in text, but that structure the act of giving meaning. Accordingly, the act of identifying these categories is an act of construction based on my reading of how the world is understood to come into being in a given text. This act of actively and purposefully identifying categories, establishes boundaries in order to momentarily suspend the embeddedness of the conceptions of transgressive learning in order to bring them closer together. Yet, this purpose defined reading with its identification of categories does not re-establish a hierarchy of binaries. In this sense, categories are not imposed as part of evaluation, but generate a productive reading of conceptions through and with one another. The constitution of categories entails by the reading-initiated dialogue and mutual engagement among positions. Thus, the reading acknowledges the multitude of conceptions (dia-logue) without judging the conception. Consequently, this paper does not outline a theory of transgressive learning as a form of definable substance, but establishes connections among different conceptions, fostering a mutual and closer engagement that accounts for a theory of transgressive learning. This perspective is possible given that these different conceptions bring into play seemingly similar categories, giving meaning differently to these categories.

Concretely, the reading consisted of actively identifying different theoretical positions about transgressive learning as they are identified to emerge in the account of the practices in the different cases. These theoretical positions were then brought into play to identify how categories of transgressive learning produce differences in and among these conceptions. The analysis identifies and puts into relation similar categories to relate the papers' theoretical positions toward transgressive learning. The structure of the presentation of results is based on the following: similarities emerging among 
theoretical conceptions in the different papers and how differences emerge when certain categories bring into play these theoretical conceptions of transgressive learning.

Based on the analysis presented in the results section, the discussion section provides a number of generative questions for the identified positions in the effort to further develop both of these positions as well as a dialogue among them, which I aim to initiate through this paper. To understand how this paper engages theoretical reduction of transgressive learning, it might be required to first define some of its key features as the diffractive reading has identified them as being shared in the different cases. In the following, I provide a basic view on shared conceptions of transgressive learning.

\section{Results}

In this section, first, general assumptions about learning and how it feeds into the project are presented (Section 3.1). This sub-section is to account for assumptions about how learning relates to transgression. Second, in Section 3.2, I aim to present different positions on transgressive learning that are constructed based on an identification of patterns of differences. It needs to be pointed out that the assumptions presented in this section are not my assumptions, but are accounts of assumptions and conceptions of transgressive learning as they were identified as part of a diffractive reading. In line with the diffractive methodology put forward, I am ascribing a particular value to an assumption or position, but the focus is to account for it. Accordingly, I do not identify with arguments, nor are they my own. Instead, I aimed to articulate and nuance implicit assumptions and positions identified within the analysed text without judgement.

\subsection{Shared Conceptions of T-Learning}

Initially, the initiation phase of the network did not restrict the meaning of " $\mathrm{t}$ " in $\mathrm{t}$-learning to either "transformative" or "transdisciplinary". These " $\mathrm{t}$ 's", which were already included in the conception of t-learning, were often determined by the participant's previous academic work and theoretical engagement. Leaving the " $\mathrm{t}$ " open to interpretation was a conscious choice as the project itself was designed to explore, rather than define, this conception of learning. The project used this strategy so the concept of the " $\mathrm{t}$ " would emerge in thought and practice in multiple contexts around the globe. Consequently, during the initial phase, it became clear that "transgression" became a way to think about generative learning as a way to experiment with disruptive forms of learning.

Based on the analysis in this paper, transgressive learning can be seen as approaches or techniques that define the current unsustainable status quo by moving beyond stubborn routines, norms, and hegemonic powers $[7,9,10]$. For example, by appealing to multiple ontologies rather than a universal ontology, researchers engaging with the concept argue that transgressive learning challenges how hegemony and the status quo conceive identity and categories. Transgressive learning must move beyond taking modes of thinking imposed by hegemony for granted if it intends to break from the present situation of unsustainable learning. However, this negative definition highlights a shared opposite (negative other) rather than a shared practical or theoretical substance, the objective of $\mathrm{t}$-learning, providing openings where new ways of thinking and action can manifest. To reformulate this line of reasoning, transgressive learning draws a magic circle around learning and the learner where the very act of creating the transgressive circle "delimits a boundary between law and transgression, the legitimate and the illegitimate, the sacred and the profane" [18]. Within transgressive learning, things are allowed to emerge, enabling the learner and the content of sustainability to break out of the routines, norms, and hegemonic powers that restrict them to the status quo. This emergence entails that transgressive learning has an essential element of playfulness and profanity as these performativities can challenge the status quo. Learning that challenges and subverts of a status quo opens up possibilities of acting differently by breaking from the assumptions that try to govern human conduct, transgressive learning opens up possibilities rather than moving towards a desired end-state. It is not aimed at a pre-determined state of sustainability (transitioning from state A to a state B conceived under the conditions of state A), but rather aims to disrupt processes of learning by engaging with sustainability 
based on a rational and emotional move beyond the apparent unchangeable status quo. This uncritical assumption of what sustainability should be is by researchers engaging with transgression in learning only partially understood as determined by hegemony, as otherwise the problem of determinism would eradicate any possibility of change at a theoretical level. I conclude that if this were the case, there would be no possibility of breaking out of the current socio-economic conditions, and learning would only reproduce an unsustainable form of capitalism. As is discussed in greater detail below, conceptions of transgressive learning are by me seen as to differ from common learning theories that focus on continuity, as it instead focuses of dis-continuity and disruption of assumptions embedded in late capitalism. In contrast to common learning theories, transgressive learning is by me interpreted to focus on the act of abandoning rather than carrying forward ways of doing and knowing. This focus also has crucial implications for transgressive learning's understanding of the role of learning and education with regards to sustainability. Rather than focusing on seeing, learning, and education as means of realizing sustainability on pre-existent knowledge and values, transgression focuses, as researchers in the project repeatedly put forward, on breaking with current unsustainable ways of being, as well as breaking with unsustainable and resilient hegemony. Accordingly, its primary focus is by me interpreted as to be on deconstruction and abandonment of unsustainable hegemonic norms, values and knowledges as an entry point for opening up and reimagining other ways of being as part of a later and secondary intervention.

If transgressive learning is to be understood as a recursive practice and theory as put forward by the analysed papers, it must address according to its own objective this crucial question: has the hegemony of a status quo truly been transgressed? In the context of the unsustainable current state of affairs, any transformative, transgressive, or otherwise change-oriented act needs to challenge its own premises, given that it emerges in a hegemony that is not fully transparent and at the same time defines the reality as it appears to us. What I would like to highlight here is the issue of the potential unsustainability of learning that focuses on a transition towards sustainability. Learning taking place in state $\mathrm{A}$, cannot assume to have transcended the problematic unsustainable hegemony that provides the conditions for reasoning in and through learning. If hegemony of the status quo determines what is assumed and therefore no longer contested, then learning that wants to contribute to social transitions towards sustainability cannot assume that visions of sustainability are not tainted by persistent, unsustainable assumptions. Consequently, I interpret assumptions about transgressive learning to assume that such learning no longer operates at the level of the political and ideological engagement with sustainability issues in education, as this level is visible in the forms of paradoxes and contradictions arising out of incommensurable ideological and political positions. Instead, transgression aims, as the papers highlight, to move beyond the hegemonic, identifying and then challenging the unexamined assumptions that inform the status quo $[9,10]$. From this theoretical position, I interpret transgression to aim to engage with the ontology of current hegemony and to move beyond that hegemony, for example, by bringing into view the possibility of parallel multiplicities of ontology excluded in the current ontological outlook sustained in the reality as defined by a status quo [19].

However, in the act of transgression, which leaves behind the reference points of what is taken for granted, positionality towards sustainability becomes difficult. Once we move beyond the assumptions underlying hegemony, a loss of orientation is inevitable, as the abandonment of the foundations for our thoughts and actions leave us at sea. This lack of an anchor makes it difficult to tell if we have transgressed a border, moving toward sustainability, as prior standards of judgement also have been transgressed. This disorienting effect of transgressive learning is captured in the underlying theory of change as developed by researchers in the t-learning network, which conceives processes of change in terms of a spiral [20]. The t-learning spiral is by me interpreted as producing an inverted form of vertigo, not occurring from great heights, but from a loss of ground or foundation that previously had been provided by the hegemony now deconstructed. Nonetheless, change can happen as we are disoriented and have lost a sense of grounding. As put forward in the analysed papers, learning shoots 
off into divergent directions, alike a seedling growing without the influence of gravity or a mutating germ cell [20,21]. In contrast to accumulative notions of learning, there is no shared reference point for judging progress towards sustainability besides the acknowledgement that certain foundations have been abandoned.

According to these assumptions, transgressive learning is by me interpreted as to challenge some of the underlying assumptions about learning and education as "transgression", which is not leading to growth or expansion of something a priori and is carried forward by the process of transgressing. In this respect, its underlying notion of learning is by me interpreted as different to cognitivist conceptions of assimilation or Deweyan pragmatist notions of growth [22,23]. Therefore, transgression in learning highlights a break, rather than continuity in learning. In fact, transgression challenges the Enlightenment's conception of the subject as essential to thought, and therefore education. In particular, the notion of the learner is, for example, in my own research in the project problematised with regards to the assumed sovereignty of that learner. The sovereignty of the Enlightenment's subject is constituted in a two-fold process: self-institution and self-limitation [24]. Sovereignty allows for the emergence of a full subject, with the capacity of self-understanding, self-consciousness, and self-representation. This conception of the learner as a self-instituting, self-representing, and self-conscious subject appeals to the most common notions of learning such as pragmatism, cognitivism, and socio-cultural theories of learning $[23,25,26]$. This self-conscious and self-instituting subject is a rational subject who slowly matures and realises, through the guidance of education, her rational potential. In this sense, rational processes of assimilation or inquiry are examples of understanding the learner in terms of the Enlightenment subject who is finally realizing her rational potential and moving towards a human destiny [27]. If we substitute the notion of human destiny or Enlightenment with sustainability, it is easy to see the parallels in reasoning.

Transgressive learning techniques and methods as developed and applied by researchers in the project attempt to subvert this notion of sovereignty, as they assume the possibility of transgressing a boundary. Transgressive learning, I argue, breaks with socio-cultural learning theories that inscribe social and non-social boundaries around the learner [26]. As I will show below, transgression in learning also challenges the assumed boundary that individuates (i.e., separates) the learner (i.e., the subject) from the world (i.e., the object), which exists outside the learner. Such a boundary around the learner partially self-limits what can be seen as a crucial assumption in thinking about learning. According to the core assumptions about transgressive learning put forward by the researchers in the paper, neither hegemony nor the learner as subject can be seen as to fully govern themselves as otherwise, I argue, transgression as an act of resisting a norm would be impossible. Transgressive learning does not assume a primary social dimension of learning, a view that is crucial for pragmatism and socio-cultural learning theory. Accordingly, transgressive learning cannot be reduced to the constitution of the learner as a member of communities of practices [28], but instead highlights the excess in learning that keeps the learner and the community from being fully constituted. If this were the case, I argue, we would end up with either a self-reproducing subject or system without the possibility of accounting for either external influence (subject) or change (system). This argumentative blind spot reflects the Enlightenment's underlying assumption that reason drives human progress. Transgression and social change arise out of excesses. I argue based on my reading that transgression appeals to a radical notion of social change that differs from cognitivist notions of accommodation, where excess can be seen to be appropriated by a pre-given human capacity to reason and the overall evolutionary human development of its ability to create knowledge as a "process of continual construction and reorganization" [29]. Contrary to assuming excess to be subsumed in an overall process or historical development, transgressive learning highlights an engagement with excess, undermining the notion of an overall historical moment or universal process. Consequently, transgressive learning undermines the core idea of human development as informing notions of sustainable development.

The subversion or transgression of the full subject takes different forms in texts published by the $\mathrm{t}$-learning network. However, all these texts attempt to problematise the notion of a sovereign 
"subject" using embodied experiences with intersectional resonances [30]. I call these "subjects" ecologised experiencing subjects. Thus, in order to produce such an ecologised subject and to produce an "engaged multi-voiced form of pedagogy" [7], which is also "empathetic and engaged" [31], transgression in learning needs to dismantle the fullness of the subject. It is here crucial to point out that this theoretical and practical dismantling of the autonomous and sovereign subject is carried out in different ways in the different practical and theoretical conceptions of transgressive learning. For example, this dismantling has by some of the researchers been carried out by highlighting the lack of self-understanding (paradoxes in the multiplicity of being), lack of self-consciousness (absence of self), and possibility to fully produce a self in processes of identification [30-32]. However, what is often shared among the researchers, is an engagement with and disruption of the hegemonic notions of the learner who is conceived as a sovereign subject. To put it into my own words, transgression moves not only outward towards a "beyond out there" (e.g., the social), but, and maybe more fundamentally and disruptively, transgression engages with a beyond that is the very core of the learner as subject. That is, transgression moves towards a "beyond that is within"; that which undermines the learners from fully constituting themselves and simultaneously providing opportunities for change to occur in transgression. Two expressions of this beyond-within are encountered in the conceptions of transgressive learning in the analysed documents: rational transgression (that which is beyond thought) and emotional transgression (that which reverberates beyond emotional resonance). These modes of transgression put forward by the researchers in the project are discussed in greater detail below. To exemplify the former documented practices of transgression, in this move towards a beyond-within, have engaged with tensions and contradictions arising in the engagement with the self as learner [30-32]. Both encounters of a beyond-within highlight an excess which undermines the boundary of the learner in acts of maintaining autonomy and self-institution. An encounter of this beyond-within highlights that the learners is, paradoxically, both an individual learner yet more than that unitary subject, as transgression undermines the act of self-institution and self-limitation.

Transgressive learning, according to the theoretical reduction, dismantles the notion of a full learner who performs acts of self-transgression. These acts and techniques of self-transgression as developed in the network's cases are engaging with in-situ experiences. In-situ experiences allow the learner to move beyond assumptions or hegemonic projections re-actualised in learning situations. That is, transgressive learning challenges the notion of learning and education determined by an overall human or social process. However, how these overall processes and consequently hegemonic projections that keep development on track are challenged is conceived differently according to the theoretical frameworks brought into play. Yet, these texts and researchers share a conviction that in-situ experience makes it possible to engage with something that I call a beyond, and which is deeper than hegemony $[9,19,31-34]$. The learning subject accesses this beyond through "situated" experiences relative to particular configurations of time and space as well as histories. Consequently, for disruption to happen, these conceptions need to assume that in-situ experiences make it possible to engage something that keeps the subject from fully instituting and limiting itself, undermining or opening up the projected sovereignty of the learner. The outcomes of transgressive learning can also be seen as negative. In learning, I interpret transgression of the self to negate, at least temporarily, the identity and limit the ability of a self to be (re)constituted $[18,35,36]$. Accordingly, the learner needs to perceive herself as different from what she assumed she was, as well as to find herself delimited or relational as a result of transgression. In this experienced negation, there needs to be an experience of excess or surplus that undermines the reproductive process of reinstituting a status quo and that renders impossible the experience of objects assumed. For transgression to challenge the subject to move beyond hegemony, it needs to show that objects and the subject have already been different or something else. Contrary to common conceptions of learning, transgressive learning with this focus on the beyond sees learning in its primary instance not as a form of appropriation or construction. Rather, transgressive learning is a form of destruction or negation that opens up for constitutive acts and responses. For sustainability, this means that transgressive learning is primarily focused on opening up 
unsustainable hegemony for destruction and negation to appropriate knowledge, values, and lifestyles contemporarily identified as sustainable. My diffractive reading suggests that there are basically two modes by which this self-transgression can be accomplished according to the papers analysed: the primarily rational and the primarily emotional.

\subsubsection{Rational Transgression in Learning}

In the case of rational self-transgression, the rational human subject engages according to this position put forward in the papers, with the paradoxes and contradictions it encounters in the constitution of meaning in experienced situations and human activity engaging with these situations [31-34]. What the learner might encounter and become aware of are ontological and epistemological differences in how a situation is given meaning through different disciplines, practitioners, cultures, etc. For example, the learner might encounter incommensurable accounts of how a sustainability issue is to be addressed in a local context. Consequently, the learner becomes aware of incompatibilities and limits of ways of being and doing, which are brought discursively into play when meaningfully engaging with a situation. Thus, the encounter of paradoxes and contradictions provides openings for critical, reflexive, and systems thinking [8]. There are then principally two ways that thinking can move out of an impasse that this encounter of paradoxes and contradictions has created: either it (re)turns to one particular way of thinking, negating the validity of some of the positions constituting a paradox (critical/reflexive thinking), or, it aims to engage in a form of sublation (systems/holistic thinking) where the differences and incommensurability among ways of thinking are sublated. Systemic and holistic thinking in learning show, according to some of the researchers, how different positions can be integrated into broader and assumed complementary ways of thinking about a sustainability issue.

However, I see the reconstitution of a path for thought to proceed is a secondary process of reconstitution that is initially opened up by the transgressive moment encountered in a perceived impasse regarding how a sustainability issue should be addressed. According to the underlying assumption of being able to break with hegemony, the transgressive moment disrupts the continuity of thought, as thought is undermined by a loss of ground and direction. As with cognitivist accounts of accommodation, thought cannot proceed as usual. Yet, rational transgression, as put forward in some of the papers, is by me interpreted as to challenge the focus on the rational subject, as the impasse is closely related to a sustainability that cannot be accommodated only by rational reconstitution. Thought loses its ground or foundation, as thought is not fully belonging to and being instituted by the subject [32]. Consequently, an impasse and the realization of the need to move forward allows for the researchers to put forward the possibility of emergence of plurality or multiplicity in the transgressive moment. I argue, that the possibility of this opening is primarily located in the insight of the loss of ground of thought, where thought directed at things is no longer pure reflection (correspondence between thought and world) but resonates in something deeper than the hegemonic status of the thing according to how humans assign meaning to the thing. Accordingly, there is not unidirectionality of thought (thought directed at something) but rather, thought is spread out. I argue, based on the assumption of the possibility of rational transgression, that thought can be seen to become transgressed by an encounter of excess, rendering directional critique and reflection impossible. To put this into the context of sustainability, a trajectory of thought that wants to constitute a sustainability issue and its solution as uni-directional, encounters complexity and wickedness in the form of an insufficiency of different positions that constitute the meaning of that sustainability issue [37]. This insufficiency could be caused by a surplus or excess of the issue at hand that cannot be reduced to a singular position. The encounter of excess ruptures the positionality of that which thought is concerned with. Consequently, thought cannot be related back to singular origin. Instead, the encounter of that excess transgresses thought. Consequently, conceptions of transgressive learning in the analysed papers acknowledge a surplus that leads inevitably to a divergence of thought. Rather than aiming to overcome this divergence through learning, transgressive learning acknowledges that rational learning needs to be 
relational or ecological and does not aim to reduce learning to the production of a uniformity of thought. Learning that reconstitutes thought after a transgression engages and observes, according to the identified rational position on transgression, the diversity of a knowledge commons without reducing knowledge to a singular hierarchy of ontology and epistemology [38]. What relates and keeps thinking common, is the shared concern with a sustainability issue; however, that thinking will be diverse as it acknowledges an excess encountered in the transgressive moment. This acknowledgment of a primary excess keeps the knowledge commons from turning into a monolithic knowledge system. In this sense, unlike for example pragmatist and cognitivist notions of learning, I interpret the rational transgression position to argue that there is no full synthesis in rational learning, where conflicting positions are reconciled into a singular position. That is, the transgressive moment as an event is acknowledged and diverse positions branch off from the transgressive moment. Therefore, a knowledge commons that addresses sustainability is not a uniform and coherent knowledge system, but a diverse configuration of trajectories of thought held together by a concern for particular sustainability issues.

\subsubsection{Emotional Transgression in Learning}

In addition to rational self-transgression, some of the analysed papers also argue for the possibility of emotional transgression [8,30-33,39,40]. For the most part, the different analysed publications highlight the cognitive, rational dimension of learning; however, some of the studies highlight the emotional and aesthetic dimension of learning in particular. My argument for such an emotional position is based on the in some of the papers identified assumption that this emotional and aesthetic dimension of learning is not reducible to thinking. For example, Kulundu highlights the rich terrain of embodied experiences as a source of transgression that allow for breaking through hegemonic structures [30]. In particular, Kulundu draws on the concept of erotic knowledge which she defines, by drawing on Lorde [41], as a "intuitive way of knowing" that is formed by the "erotic—the sensual—-those physical, emotional, and psychic expressions of what is deepest and strongest and richest within each of us" [41]. This intuitive knowing relates to an emotional resonance, a feeling of what is the deepest within us as Lorde expresses it [41]. Kundulu's conception of transgressive learning involving erotic knowledge, alters the conditions for understanding learning as it is no longer a primarily rational intuition (as proposed by Kant), but a physical and emotional intuition. I argue, that the conception of emotional transgression relating to this physical and emotional intuition breaks with core assumptions about learning as expressed in, for example, cognitivism, pragmatism, and socio-cultural theory with their preoccupation of rational development. Emotional transgression challenges the assumption that processes of learning are primarily developing a rational identity of the learner. Accordingly, this emotional and embodied intuitive way of knowing highlights dissonance between a rational conception of one's identity and the feeling emanating from the depth of our within that reminds us of what we are. In this understanding, emotion entails transgressing rational self-institution. Similarly, I argue in my own research in the project that feelings and emotions highlight a certain absence of self, a self that is not truly present to me, but is real, something I have a certain emotional connection to and anticipation of [32]. Emotions in this sense have the potential to transgress cognitive repetition in acts of identification with what it means to be and act sustainable. Emotions give the learner a feeling of dissonance between the cognitive attempt to constitute identity and that which is to be constituted. In particular, the emotion of empathy can, according to McGarry's conceptions of transgression, be seen as pulling the subject out of itself [19,33], providing a form of initial equality as a basis for learning as the concept of "empathetic apprentice" highlights [42]. Empathy can transgress patterns of thinking about what it means to act sustainable by becoming emotionally aware of how this pattern might be exclusive of or even inflicting violence on other ways of being. That is, emotions can be seen as prerequisites for transgression in learning, as learning is often not reducible to either cognition or emotions, but entails both. 


\subsection{Central Categories for Conceiving T-Learning}

When it comes to reducing the plurality of central concepts in transgressive learning to certain central categories, such categories are somewhat artificially extracted. They are artificially extracted, as I understand categories, because they represent a priori distinctions brought into play in order to discern between relata and relations [43]. Categories are in the different conceptions brought differently into play such as making relations possible. However, categories usually come in close entanglement with a mutually constitutive concept, i.e., the relata are differentiated by the categories. There are several central categorial conceptual combinations: individual/collective learning, disruptive/systemic learning, and hegemonic ontology/multiple realities or ontologies. These categorial combinations are, according to my reading of the analysed papers, positioned for maximum contradictions, amplifying binary paradoxes. You might argue that this sounds contra intuitive to the ambitions of transgressive learning, yet I see these categories and others to be brought into play by the different researchers in the project to create dynamisms for critical and reflexive engagement. This observation is based on the arguments put forward in the analysed papers that transgressive learning attempts to disrupt Western binary thinking [7], while simultaneously bringing into play such binaries when constituting transgressive learning [17]. To sum up the core assumption about engaging with binary conceptions in transgression appealed to in the analysed papers, transgressive learning engages with the excesses that excluded in attempts to reduce the world to binary conceptions. Based on this assumption, I interpret the papers to argue that this excess makes the emergence of concepts that lie outside binary thinking possible. Without a boundary, there is no transgression, yet transgression challenges the integrity of the boundary (inside/outside) in the first place.

\subsubsection{Individual/Collective Learning}

A crucial categorial configuration for transgressive learning is the distinction between individual and collective learning and consequently the primary distinction between individual subject and the collective subject. How the relation between the two categories is understood differs in relation to the theoretical framework brought into play by the researchers in the analysed papers. However, I argue, the concept of transgression highlights the individual aspect and to some extent suspends the collective dimension of learning. Transgression highlights the subversion of a boundary or norm, where a norm is quintessentially social or collective in nature. In this sense, transgressive learning is not simply an antagonistic form of social learning, i.e., it does not simply aim to replace one norm with another, but is primarily concerned with transgressing any norm or boundary to open up new ways to engage with sustainability. Unlike traditional education, transgressive learning does not aim at socializing and inserting the individual learner into a sustainable social whole as this whole is initially seen as defined by problematic, unsustainable hegemony $[7,10]$. Transgressive learning differentiates, for example, transgressive learning from transformative or social learning [7,44,45]. At the same time, by problematising educational philosophy's focus on learning [46,47], transgressive learning does not appeal to an individualistic notion of education. Transgression requires the prerequisite of a norm to be transgressed as well as orienting itself towards the context of engaging with a sustainability issue. It acknowledges the place and time of the experienced transgression when engaging with that issue. However, this context seems unable to determine the individual learner in a sense that it would fully position her in a web of relations.

As Schudel [48] highlights in her critical realist account of environmental learning within the network, that the identity of the learner is to be understood in relation to the learners' "thrownness" [49] into a world or context. Interpreting this thrownness in Heideggerian terms, thrownness refers to being in a context, or rather, being in the world that does not attempt to impose a position the learner must attain; rather, given the arbitrary experience of being thrown in the world, in action, and in reason, the learner makes choices based on, but not determined by, social convention [50]. For Schudel, this thrownness relates to an integral understanding of "what is" and "what is not" [48]. Because of thrownness, an individual can transgress social convention. If there were not such an individual 
identity but only a subject position existing according to social convention, we would withhold the possibility of both transgression and change of unsustainable hegemony. At the same time, the individual cannot be fully a self (i.e., a self that is self-instituting and self-limiting), as this would render any form of connection to the world only secondary and the individual would be able to establish itself as fully autonomous and isolated. However, the complexity and wickedness of nexus issues of sustainability addressed by transgressive learning remain whether the individual learner chooses to engage these issues or brackets them from their daily thinking and experience. As Schudel [48] notes, these issues are real and not reducible to individual interpretation. Schudel [48] is appealing to a critical realist acknowledgement of the real and consequent focus on the conditions of possibility for human knowledge of things in the first place. Here, we are addressing the transcendental realist condition of there being a world in the first place that human beings are thrown into [51]. A world must exist before human existence and experience. Accordingly, transgression according to this crucial realist outlook highlights that the individual is entangled with the collective, but also with a world that is not congruent with human experiences of events taking place in the world. That is, this non-congruence between the world as it is and human experience of it allows excess. This excess, I argue, renders the possibility of transgression as well as the divergence between the individual and the collective. Therefore, it is possible for the individual, rational human being to become aware of an excess in the world as it appears, that does undermine any singular correspondence and human reduction of a world-in-itself to a world-for-us, rational human subjects. The realist position, as appealed to by some of the papers analysed, wards off the danger of reducing the encountered non-congruence to a form of individual interpretation, as the conditions for that experience and consequently interpretation are real. Climate change does not disappear if I or humans collectively choose to interpret it as fake news, rather climate change is based on these ontological considerations: a critical realist account of transgression allows for the possibility of excess and how a boundary might both be there and not be there at the same time. To reformulate this into non-critical realist terminology, there might be a real boundary between objects, as they intuitively appear as continuous entities, yet the boundary is never fully apprehended. Excess is constituted by appealing to the non-congruence between a real boundary and a boundary as it appears. Transgression is possible and engages with the opaqueness of boundaries that must be there, yet not fully apprehended. Accordingly, the boundary is simultaneously there and not there and it is this paradox that allows it to be transgressed. The excess allows for a notion of having something in common (a world with environmental problems we find ourselves thrown in) without reducing it to a singular human rational subject that as a whole (collective) would account for it.

\subsubsection{Disruptive/Systemic Learning}

Transgressive learning, as conceived in the analysed papers, fosters both sides of the categorial binary disruptive/systemic learning. The disruption feeds on and opens up possibilities for changes within a system [19], moving, for example, beyond unsustainable hegemony. The conditions for disruption arise from an excess within the system that the human learner finds herself thrown into. Paradoxically, for disruption to become possible, a system has to function and not function at the same time. For example, when Lotz-Sisitka et al. envision transgressive learning as arresting systemic dysfunction and systemic violence and challenging hegemonic power, the system's ability to function is somewhat limited [7]. Lotz-Sisitka believes emergence is only possible because of the openness of systems, where that openness is a condition for new constellations and conditions [38]. Olvitt refers here to the Anthropocene as a process of becoming aware that humans are part of a laminated whole, a system "nested in, emergent from, but not reducible to one another" [40]. However, it is unclear how this system as a whole relates to the different systems that she sees compose that system:

"Importantly, these laminated systems are open systems, that is, they are in constant, probabilistic interaction with one another, producing a dynamic and relational ontological whole that allows the contingencies of structures and mechanisms at multiple levels to inter-relate with human agency." [40] 
The point to be made here is that transgression, based on the arguments put forward above, can challenge the very notion of open systems. In systems theory, open system refers to systems that interact with something that is external to that system. Conceiving of an open system entails a conception of a boundary, a boundary that distinguishes between what is internal and external to that system. Yet, as Olvitt [40] highlights, these systems are laminated rather than a priori distinct systems. Given the focus on in-situ experience of transgressive learning, the learner might primarily encounter a laminated topology rather than abstract space when engaging with sustainability issues. As it is possible to move beyond a layer of that laminated topology, the laminations have to be secondary constructs to a primary encounter of an overlaying lamination. Consequently, transgression, I argue, highlights the translucency of any system boundary. This translucency is also highlighted in the issues that transgressive learning address, i.e., wicked and complex sustainability issues. Wickedness implies the impossibility of accounting for a whole, a system, based on what is happening in it. The wickedness of sustainability issues implies that they are unverifiable although real [52].

With the dynamic topology of experience in mind, emergence can only be seen to become possible when we start with a topological view on local manifestations of, for example, wicked sustainability problems rather than assuming static boundaries that would allow different systems to remain distinct and to fully determine what is internal and external to a given system [53]. Accordingly, anything has to be more than the sum of its position within a system or among laminated systems in order for a form of change and emergence to be possible. Transgressive learning is, as Lotz-Sisitka et al. characterise it, critical, empathetic, connective, dialogical, radical, and explicitly normative as it relates to the excess that undermines any system from fully functioning [7,9]. This might entail that a system as well as a learner would have to be open as we discussed in the conception of an ecologised experiencing subject. For a learner to open herself up and to make herself vulnerable intellectually, bodily, and emotionally, transgression is potentially a way for the learner to encounter more than what her bounded assumptions reveal $[7,54]$. Transgressive learning highlights to the learner that both the content of learning as well as her identity are not (yet) determinable. That is, the learner is open and consequently engaging with sustainability issues as content will through learning alter the learner's identity.

\subsubsection{Universal Ontology/Multiple Ontologies}

How this being more than what one assumes to be (i.e., having multiple ontologies) is conceptualized in the different papers, varies according the ontological outlook brought into play when conceiving a transgression. I already touched on ontological issues and outlooks when some of the papers raised the issue of what is (presences) and what is not (absences) $[38,48,54]$. Ontology as a sub-field of metaphysics deals in principle with two central questions: (1) what is? And, (2) how is it? The first question, as raised by Schudel [48], deals with the issue of what exists and has often been dealt with by delineating what is real and what is not real. For example, atomism, which frames many strands of natural sciences, is based on a particular ontological outlook that assumes that what is can be determined by reference to atomic or subatomic entities that the world is made of. Schudel's binary construction of the question of "what is" and "what is not" can be seen to share two crucial ontological assumptions: (1) how things are can be defined in terms of presences and absences, and (2) how things are relates to a (singular) world [48]. Thus, what is real, or what exists, is determinable as either being there or not being there. The crucial point to be made here is that reality according to this outlook is relative to a singular world, even though this world might be made of different strata [51]. We might speak here of an ontological outlook that appeals to a singular ontological state. Here, I use the Heideggerian understanding of the term ontological as referring to the deeper underlying structures of reality as different from the ontic, which refers to the concrete specific realities [50]. According to a critical realist perspective on transgressive learning, as appealed to in some of the analysed papers, the ontological represents the transcendental conditions for how things are in concrete and specific experiences $[34,38,40,54,55]$. Ontically speaking, what is and what is not are determined by the deeper ontological conditions and the surface human projections (discourses, hegemony, etc.) that shape of 
how things appear as specific and concrete realities. In this sense, learning needs to move beyond human projections and conceptions of sustainability and address sustainability by considering how things and issues are in the world irrespective of human projections. Learning that wants to move hegemony needs to tap into a negativity that could disrupt the assumptions about the appearance of the world. Accordingly, to reformulate the use of negativity appealed to by critical realist conceptions of transgressive learning, negativity relates to the non-congruence between the ontological and the ontic, which entails a differentiation between a universal mode in which things are and the concrete and specific mode in which they are. Transgression becomes in this position possible when engaging this negativity, which I have labelled above as excess. That is, there are two crucial categories brought into play when trying to understand transgressive learning: a universal ontological outlook as described above, and an appeal to multiple ontological outlooks as understood by Macintyre and Chaves [19,31].

Macintyre and Chaves speak of "other" worlds, worlds out there, that constitute a pluriverse [31]. Chaves et al. define this pluriverse in terms of one world being multiple worlds or consistent of a multiplicity, and call for relational ontologies to replace a homogenizing ontology [19]. According to this outlook, transgression takes place in learning that reveals the many worlds which are engaged in these particular issues. To be precise, Chaves et al. relate ontology to existence, being, and knowing and closely intertwine the three in their ontological outlook "that people learn more from each other when they are confronted by different realities-what exists, and our underlying assumptions of what is, what is not and what might be" [19]. In contrast to the singular notion of an underlying reality that differs from the ontic, this position rejects such a foundational reality as standing in a negative relation to the ontic. Chaves et al. attain a "pragmatic" notion of reality, which holds

"that the reality we live in is one performed in a variety of practices, whereby reality does not precede the everyday practices in which we interact with 'the world', but is rather shaped within those practices. Since practices are multiple, so too are the realities they produce-hence, 'if reality is done, then it is also multiple'". [19]

Consequently, it can be argued that the pluriverse inverts the relation between the ontic and the ontological as outlined in relation to the critical realist outlook. The ontic is what is real, and as the quotation above notes, there is no reality preceding everyday practices. Encountering the pluriverse entails a transgression between realities as it is in the concrete engagement with the world that the world and also sustainability issues are made real. Therefore, the appeal to a pluriverse puts forward an ontological position that is idealist rather than realist as the pragmatic notion of reality requires a human subject as a point of reference for reality. The pluriverse requires the presence of a human participating in activity for the world or a sustainability issue to become real. Accordingly, the world realizes itself differently according to the variety of "cultural" practices that bring it into being. These practices, however, are according to this outlook seen as "partially connected" [19]. These worlds are connected, according to other conceptions of the pluriverse, given a colonial matrix of power (CMP) as "a complex structure of management and control composed of domains, levels, and flows" centred around the principles and ideas of coloniality/modernity [56]. This CMP functions primarily through rhetorical devices of modernity that define the levels of the CMP and puts it in relation to different levels given the rules, assumptions, and principles of conversations that can become possible [56]. The potential for excess is inherent to the prevalence of alternate ontologies/cosmologies relative to non-Western cultures, which in their difference constitute other ways of bringing the world into reality. According to this identified position that argues for multiple ontologies, transgressive learning feeds on excess to engage with "power-laden ontological interactions, interferences and blendings that are characteristic of complex socio-ecological settings" [19]. To reformulate this into the context of the discussion of excess, the excess stems from cultural differences and consequent ontological conflicts that can allow for the emergence of "space for reflection through disruption and dissonance" [19]. Dissonance becomes constructive as it is not sublated with regards to an external reference point, but through negotiations and inclusive engagement. This dissonance, however, requires a form of negotiation that appeals to new types of knowledges, skills, and methodologies [19]. Dissonance 
also requires a form of openness from the learner to engage in an ontological dialogue that requires "the capacity to move in and relate ways of knowing and being that partly overflow one another, yet without a-priori assuming one to be superior" [19]. Transgressive learning engages with sustainability issues by moving between different ways of being, where these moves produce different worlds and open up for the emergence of other worlds and futures.

By combining both the mono-ontological outlook of transgressive learning drawing on critical realism and the multiple ontologies outlook that appeals to the pluriverse, change or openness to the world is possible as it emerges in the excess between a claim of what is and what is not. Learning is actively engaging with this excess, or the between of what is and what is not, to open up possibilities for challenging unsustainable hegemony. Hegemony in this sense requires a continued appeal to a status quo, a state of things in which that state can be determined in relation to what is. To be precise, transgressive learning engages with the systemic suppression of excess through education and learning. Transgressive learning engages with this surplus as it haunts any attempt to reproduce that which is assumed, as hegemony relies on providing core assumptions of what is and what is not. Transgressive learning engages with excess to open up alternative ways and more sustainable ways of being. This excess is not external or beyond the boundary, but relates to the elusiveness of any boundary, whether the boundary is a thing within a system or the boundary of the system itself.

\section{Discussion}

The previous section aimed to present the results of my diffractive reading and the attempt to engage in a theoretical reduction of the conception of transgressive learning. Here, the focus was primarily on an account of other texts and patterns of similarities and differences in the analysed text. In this section, I aim to actively engage in a dialogue with the authors of these texts and other interested parties in order to actively make an effort to push for future development of a theory of transgressive learning. I actively raise certain issues for future clarification.

I will be doing this by raising several generative questions to stimulate further theoretical development of transgressive learning in its divergent conceptions. The questions address the overarching ambition of transgressive learning to move beyond stubborn routines, norms, and hegemonic powers that define the current unsustainable status quo [7,9]. How this ambition can be realised through learning will be conceived differently given the theoretical differences portrayed in this paper. My questions are to be interpreted to identify and address potential gaps, blind spots and paradoxes in the conceptions of transgressive learning so far. Also, in this case, they are not indented to argue for the supreme value or superiority of a particular position or outlook on transgressive learning, but rather I envision these questions to continue and nuance the development of different outlooks and positions. Yet, at the same time I enter my own interpretative outlook to point out potential pitfalls as well as promising opportunities.

Question 1: how does transgression relate to both continuity and change in learning?

As transgression attempts to move beyond a status quo, the unsustainable state in which things are currently, it is crucial to conceptualise more thoroughly in what way transgressive learning will entail a form of reproduction (continuity) and/or change. The point is to clarify to what extent transgressive learning contributes to something that radically differs from the norms, routines, and discourses of contemporary hegemony. An answer would need to clarify what changes and what is reproduced in learning. For example, it might be crucial to clarify how transgression leads to change and transformations at the micro, meso, and macro levels of systems, as well as what remains continuous at these levels. These levels refer to artificially constructed scales that are differentiated according to phenomena that are either accessible or inaccessible to a human subject. An appeal to process-oriented philosophy that sees things in a state of continuous change (becoming) might here be problematic given the problematisation of the resilience of unsustainable systems that are precisely calling for alternate ways of learning that do not reproduce these systems $[7,9]$. 
Question 2: how to conceive of the temporal dimension of transgression in learning and its effects?

It is important to clarify the question of how to conceive of the time of continuity and change in learning. When is change taking place? When is learning achieved or approximated sustainability achieved? When is transgressive learning solved or sufficiently addresses a sustainability issue? Might transgression, for example, highlight that change already could have taken place and hence not be a "result" of learning? In addition, it would also be of interest to interrogate teleological notions of macro-scale change in the moment of transgression. Does transgression assume that change has to relate to an overall shift in the state of things at the macro level (social transformation)? If not, what ontological primacy would change at the micro level have for the conception of shifts at the meso and macro level? To use the notion of niche as appealed to in order to conceive of the possibility of systemic change [7], we might reconsider the emergence of cracks and windows of opportunity that transgression opens up: "niche-innovations may break through more widely if external landscape developments create pressures on the regime that lead to cracks, tensions and windows of opportunity" [57]. In this understanding, changes at higher level states (i.e., the external landscape developments) determine the possibility of change at lower levels. Paradoxically, social transformation, according to this understanding, can be interpreted to be determining the possibilities for learning to foster sustainable learners. With the discussion of ontology and excess in mind, transgressive learning can be seen to emphasise that what becomes possible in learning is not so much that the learner is becoming aware of alignments and developments among different levels or dimensions, as determined by an overarching temporal state of things seen from a macro perspective (developments), but that a learner is becoming aware of a misalignment or non-alignment of levels given an encountered excess in in-situ experiences at the micro level [57]. In this experience of excess, there is not one external temporal time frame, but many entangled times. Transgressive learning can therefore be seen to open up for a radically different understanding of the alignment between education and development of humanity. Counter to the Enlightenment vision of seeing education as a premise for the development of humanity as a whole and overall historical progression, transgressive learning encourages shoot-offs of continuity as well as divergence in development. It is here that transgressive learning opens up for a radical different understanding of possibility of change in learning, as it breaks with common notions of holism in educational thought. Transgressive learning is decoupled from a singular historical movement and an overarching process of social transformation, yet at the same time entailing change at different levels.

Question 3: how could transgressive learning be further developed to challenge underlying hegemonic assumptions about learning and what it means to be a learner?

As noted throughout this paper, transgressive learning challenges hegemonic structures. Such structures not only refer to broader social assumptions and ways of being, but also refer to assumptions informing our thinking about education and what it means to be a learner. My last generative question is an invitation to further question the basic assumption about what it means to learn and to be a learner in the context of sustainability. The task of rethinking learning and what it means to be a learner can be seen as crucial for breaking with reproducing unsustainable ways of being and doing in education. For example, transgressive learning can in many ways be seen to require an active human subject that engages in and initiates an act of transgression and moves toward sustainability. Might transgression also be something that happens to the learner? To learn might entail in this notion a non-intentional transgression by something else. Alternatively, might transgression and the somewhat opaqueness of any boundary also blur any conception of a separation of a learner from that which she is not? Returning to the undermining moment of the sovereignty of the human subject as learner in transgression, does this not also challenge the limit or self-limitation of that learner in the act of transgression [24]? For example, with regards to the embodiment of the in-situ experience of the learner, the learner might ask where does my bodily experience end or where is its limit [30]? Would the "us" as in "within us" accessed in intuitive knowledge be somewhat opaque and displaced? 


\section{Conclusions}

This paper aims to engage in a theoretical reduction of transgressive learning. As it hopefully has become apparent, there is an abundance of traces within the diversity of its conceptions that in their divergence open up new entry points for engaging with learning and education aimed at opening up possibilities for change and more sustainable ways of being rather than reproducing unsustainable social structures and dynamics. Furthermore, the theory of transgressive learning is a theory in the making. This theory making is embedded and engages with concrete struggles, injustices, and matters of concern in their particular local manifestations. Given this focus and engagement, I argue its richness, subtleness, and refinement of flavours acknowledged. This understanding does not rely on a pre-defined path for future theoretical development. Rather, given its embeddedness in living contexts and diversity of theoretical orientation, it is a dynamic theory allowing for the possibility of radically rethinking what learning and education for sustainability might become. Consequently, this paper is not a main course that represents the work of the t-learning project members and communities, but rather is served as an appetizer to consume with greater attentiveness and curiosity about the works cited in this paper and to follow emergent publications of their authors.

Funding: This research was funded by the International Social Science Council (ISSC) (now International Science Council) grant number TKN 150314115141.

Acknowledgments: I would like to thank Anna James for her comments on the initial draft of this paper. In addition, I would like to thank the anonymous reviewers for their suggestions on how to improve this paper and to strengthen and streamline its argumentation. Last, but not least, I would like to thank the members of the $\mathrm{t}$-learning network for their inspiring work and for their interest in my own work during the project.

Conflicts of Interest: The authors declare no conflict of interest

\section{Appendix A List of Analysed Publications}

Belay, A.M. Using critical realism to explain change in the context of participatory mapping and resilience. In Critical Realism, Environmental Learning and Social-Ecological Change; Price, L., Lotz-Sisitka, H., Eds.; Routledge: London, 2016; pp. 40-61.

Bengtsson, S.L. Outlining an Education Without Nature and Object-Oriented Learning. In Research Handbook on Childhoodnature; Cutter-Mackenzie, A., Malone, K., Hacking, Barratt, E., Eds.; Springer, 2018; pp. 1-22.

Chaves, M.; Macintyre, T.; Verschoor, G.; Wals, A.E.J. Towards Transgressive Learning through Ontological Politics: Answering the "Call of the Mountain" in a Colombian Network of Sustainability. Sustainability 2017, 9.

Kulundu, I. Change Drivers at the front lines of the future: rising cultures for sustainability education in contemporary South Africa. In Envisioning futures for environmental and sustainability education; Corcoran, P.B., Weakland, J., Wals, A.E.J., Eds.; Wageningen Academic Publishers: Wageningen, 2017; pp. 419-426.

Kulundu, I.; Africa, S. Intersectional Resonance and the Multiplicity of Being in a Polarised World. South. African J. Environ. Educ. 2018, 34, 91-100.

Lotz-sisitka, H. Education and the Common Good. In Post-Sustainability and Environmental Education; Jickling, B., Sterling, S., Eds.; Palgrave Macmillan: London and New York, 2017; pp. 63-76 ISBN 9783319513225.

Lotz-Sisitka, H.; Ali, M.B.; Mphepo, G.; Chaves, M.; Macintyre, T.; Pesanayi, T.; Wals, A.; Mukute, M.; Kronlid, D.; Tran, D.T.; et al. Co-designing research on transgressive learning in times of climate change. Curr. Opin. Environ. Sustain. 2016, 20, 50-55.

Lotz-Sisitka, H.; Wals, A.E.J.J.; Kronlid, D.; McGarry, D. Transformative, transgressive social learning: Rethinking higher education pedagogy in times of systemic global dysfunction. Curr. Opin. Environ. Sustain. 2015, 16, 73-80.

Macintyre, T.; Chaves, M. Balancing the Warrior and the Empathic Activist: The Role of the Transgressive Researcher in Environmental Education. Can. J. Environ. Educ. 2017, 80-96. 
Macintyre, T.; Lotz-Sisitka, H.; Wals, A.; Vogel, C.; Tassone, V. Towards transformative social learning on the path to 1.5 degrees. Curr. Opin. Environ. Sustain. 2018, 31, 80-87.

Macintyre et al. Educating for development or educating for the good life - Buen vivir imaginaries and the creation of one's own myth. In Envisioning futures for environmental and sustainability education; Corcoran, P.B., Weakland, P., Wals, A.E.J., Eds.; Wageningen Academic Publisher: Wageningen, 2017; pp. 193-204.

McGarry, D. Empathetic apprentice: Pedagogical developments in aesthetic education of the social learning practitioner in South Africa. In Intergenerational learning and transformative leadership for sustainable futures; Corcoran, P.B., Hollingshead, B.P., Lotz-Sisitka, H., Wals, A.E.J., Eds.; Wageningen Academic Publishers: Wageningen, 2014; pp. 189-200.

McGarry, D. The Listening Train: A Collaborative, Connective Aesthetics Approach to Transgressive Social Learning. South. African J. Environ. Educ. 2015, 31.

Mickelsson, M.; Kronlid, D.O.; Lotz-Sisitka, H. Consider the unexpected: scaling ESD as a matter of learning. Environ. Educ. Res. 2018, 0, 1-16.

Mukute, M. Dialectical Critical Realism and Cultural Historical Activity Theory (CHAT): exploring and expanding learning processes in sustainable agriculture workplace contexts. In Critical Realism, Environmental Learning and Social-Ecological Change; Price, L., Lotz-Sisitka, H., Eds.; Routledge: London, 2016; pp. 190-211.

Olvitt, L.L. Education in the Anthropocene: Ethico-moral dimensions and critical realist openings. J. Moral Educ. 2017, 46, 396-409.

Pesanayi, T. Exploring contradictions and absences in mobilizing 'learning as process' for sustainable agricultural practices. In Critical Realism, Environmental Learning and Social-Ecological Change; Price, L., Lotz-Sisitka, H.., Eds.; Routledge: London, 2016; pp. 230-253.

Peters, M.A.; Wals, A.E.J. Transgressive learning in times of global systemic dysfunction: interview with Arjen Wals. Open Rev. Educ. Res. 2016, 3, 179-189.

Schudel, I.J. Modelling Dialectical Processes in Environmental Learning: An Elaboration of Roy Bhaskar's Onto-axiological Chain. J. Crit. Realis. 2017, 16, 163-183.

\section{References}

1. United Nations Framework Convention on Climate Change. UN Climate Change Annual Report 2017; UNCC: Bonn, Germany, 2017.

2. UN. United Nations Framezork Convention on Climate Change Article 6; UNCC: Bonn, Germany, 1992.

3. Mezirow, J. Transformative Dimensions of Adult Learning; Jossey-Bass Publishers: San Francisco, CA, USA, 1991.

4. Mezirow, J. Learning as Transformation: Critical Perspectives on a Theory in Progress; Jossey-Bass Publishers: San Francisco, CA, USA, 2000.

5. Taylor, E.W. Transformative Learning Theory. In Transformative Learning Meets Bildung: An International Exchange; Laros, A., Fuhr, T., Taylor, E.W., Eds.; Sense Publishers: Rotterdam, The Netherlands, 2017; pp. 17-29, ISBN 978-94-6300-797-9.

6. Illeris, K. Transformative Learning in the Perspective of a Comprehensive Learning Theory. J. Transform. Educ. 2004, 2, 79-89. [CrossRef]

7. Lotz-Sisitka, H.; Wals, A.E.J.; Kronlid, D.; McGarry, D. Transformative, transgressive social learning: Rethinking higher education pedagogy in times of systemic global dysfunction. Curr. Opin. Environ. Sustain. 2015, 16, 73-80. [CrossRef]

8. Macintyre, T.; Chaves, M.; Villa-Barajas, S.; Makú-Pardo, A. Educating for development or educating for the good life - Buen vivir imaginaries and the creation of one's own myth. In Envisioning Futures for Environmental and Sustainability Education; Corcoran, P.B., Weakland, P., Wals, A.E.J., Eds.; Wageningen Academic Publisher: Wageningen, The Netherlands, 2017; pp. 193-204.

9. Lotz-Sisitka, H.; Ali, M.B.; Mphepo, G.; Chaves, M.; Macintyre, T.; Pesanayi, T.; Wals, A.; Mukute, M.; Kronlid, D.; Tran, D.T.; et al. Co-designing research on transgressive learning in times of climate change. Curr. Opin. Environ. Sustain. 2016, 20, 50-55. [CrossRef] 
10. Macintyre, T.; Lotz-Sisitka, H.; Wals, A.; Vogel, C.; Tassone, V. Towards transformative social learning on the path to 1.5 degrees. Curr. Opin. Environ. Sustain. 2018, 31, 80-87. [CrossRef]

11. T-learning. Our Writing-Some Academic Papers from the t-Learning Team; T-Learning: Grahamstown, South Africa, 2018.

12. Barad, K. Meeting the Universe Halfway: Quantum Physics and the Entanglement of Matter and Meaning; Duke University Press: Durham, NC, USA, 2007.

13. van der Tuin, I. Reading Diffractive Reading: Where and When Does Diffraction Happen? Disrupting Humanit. Towar. Posthumanities 2016, 19. [CrossRef]

14. Barad, K. Erasers and erasures: Pinch's unfortunate 'uncertainty principle'. Soc. Stud. Sci. 2011, 41, $443-454$. [CrossRef]

15. Barad, K. Quantum Entanglements and Hauntological Relations of Inheritance: Dis/continuities, SpaceTime Enfoldings, and Justice-to-Come. Derrida Today 2010, 3, 240-268. [CrossRef]

16. Derrida, J. Of Grammatology, 1998th ed.; John Hopkins University Press: Baltimore, MD, USA, 1967.

17. Harman, G. Barad's Entanglements and Transcontextual Habitats. Rhizomes Cult. Stud. Emerg. Knowl. 2016, 30, 1-23.

18. Thacker, E. In the Dust of this Planet; Zero Books: Winchester, VA, USA; Washington, DC, USA, 2011.

19. Chaves, M.; Macintyre, T.; Verschoor, G.; Wals, A.E.J. Towards Transgressive Learning through Ontological Politics: Answering the "Call of the Mountain" in a Colombian Network of Sustainability. Sustainability 2017, 9, 21. [CrossRef]

20. McGarry, D. Visual representation of t-learning 2017. In Proceedings of the T-Learning Meeting, Visby, Sweden, 5-9 July 2017.

21. Mickelsson, M.; Kronlid, D.O.; Lotz-Sisitka, H. Consider the unexpected: Scaling ESD as a matter of learning. Environ. Educ. Res. 2019, 1, 135-150. [CrossRef]

22. Dewey, J. Experience and Nature; George Allen \& Unwin, Ltd.: London, UK, 1928.

23. Piaget, J. Barnets själsliga utveckling; Studentlitteratur: Lund, Sweden, 2013.

24. Mbembé, J.; Meintjes, L. Necropolitics. Public Cult. 2003, 15, 11-40. [CrossRef]

25. Dewey, J. The School and Society. In The School and Society: Being Three Lectures; University of Chicago Press: Chicago, IL, USA, 1900; pp. 1-29.

26. Vygotsky, L.S. Mind in Society; Harvard University Press: Cambridge, MA, USA, 1978.

27. Kant, I. What is Enlightenment? In Kant: Political Writing; Reiss, H.S., Ed.; Cambridge University Press: Cambridge, UK, 1970.

28. Rogoff, B. Apprenticeship in Thinking: Cognitive Development in Social Context; Oxford University Press: New York, NY, USA, 1990; ISBN 0-19-505973-5.

29. Piaget, J. Genetic Epistemology; W.W. Norton \& Company: New York, NY, USA, 1970.

30. Kulundu, I. Intersectional Resonance and the Multiplicity of Being in a Polarised World. Available online: https://www.ajol.info/index.php/sajee/article/view/172212 (accessed on 12 June 2019).

31. Macintyre, T.; Chaves, M. Balancing the Warrior and the Empathic Activist: The Role of the Transgressive Researcher in Environmental Education. Can. J. Environ. Educ. 2017, 80-96.

32. Bengtsson, S.L. Outlining an Education Without Nature and Object-Oriented Learning. In Research Handbook on Childhoodnature; Cutter-Mackenzie, A., Malone, K., Hacking Barratt, E., Eds.; Springer: Berlin, Germany, 2018; pp. 1-22, ISBN 978-3-319-51949-4.

33. McGarry, D. The Listening Train: A Collaborative, Connective Aesthetics Approach to Transgressive Social Learning. S. Afr. J. Environ. Educ. 2015, 31, 8-21.

34. Belay, A.M. Using critical realism to explain change in the context of participatory mapping and resilience. In Critical Realism, Environmental Learning and Social-Ecological Change; Price, L., Lotz-Sisitka, H., Eds.; Routledge: London, UK, 2016; pp. 40-61.

35. Gramsci, A. The Prison Notebooks; Columbia University Press: New York, NY, USA, 1992.

36. Englund, T. Curriculum as a Political Problem: Changing Educational Conceptions, with Special Reference to Citizenship Education; Acta Universitatis Upsaliensis: Uppsala, Sweden, 1986.

37. Rittel, H.W.J.; Webber, M.M. Dilemmas in a general theory of planning. Policy Sci. 1973, 4, 155-169. [CrossRef]

38. Lotz-sisitka, H. Education and the Common Good. In Post-Sustainability and Environmental Education; Jickling, B., Sterling, S., Eds.; Palgrave Macmillan: London, UK; New York, NY, USA, 2017; pp. 63-76, ISBN 9783319513225. 
39. Kulundu, I. Change Drivers at the front lines of the future: rising cultures for sustainability education in contemporary South Africa. In Envisioning Futures for Environmental and Sustainability Education; Corcoran, P.B., Weakland, J., Wals, A.E.J., Eds.; Wageningen Academic Publishers: Wageningen, The Netherlands, 2017; pp. 419-426.

40. Olvitt, L.L. Education in the Anthropocene: Ethico-moral dimensions and critical realist openings. J. Moral Educ. 2017, 46, 396-409. [CrossRef]

41. Lorde, A. Sister Outside: Essays and Speeches; Crossing Press: New York, NY, USA, 2007.

42. McGarry, D. Empathetic apprentice: Pedagogical developments in aesthetic education of the social learning practitioner in South Africa. In Intergenerational Learning and Transformative Leadership for Sustainable Futures; Corcoran, P.B., Hollingshead, B.P., Lotz-Sisitka, H., Wals, A.E.J., Eds.; Wageningen Academic Publishers: Wageningen, The Netherlands, 2014; pp. 189-200.

43. Bryant, L.R. Relata Do Not Precede Relations. Available online: https://larvalsubjects.wordpress.com/2012/ 09/27/relata-do-not-precede-relations/ (accessed on 12 June 2019).

44. Chaves, M.; Macintyre, T.; Riano, E.; Calero, J.; Wals, A. Death and rebirth of Atlántida: The role of social learning in bringing about transformative sustainability processes in an ecovillage. S. Afr. J. Environ. Educ. 2015, 31, 22-32.

45. Peters, M.A.; Wals, A.E.J. Transgressive learning in times of global systemic dysfunction: interview with Arjen Wals. Open Rev. Educ. Res. 2016, 3, 179-189. [CrossRef]

46. Simons, M.; Masschelein, J. From schools to learning environments:The dark side of being exceptional. J. Philos. Educ. 2008, 42, 687-704. [CrossRef]

47. Simons, M.; Masschelein, J. Governmental, political and pedagogic subjectivation: Foucault with Rancière. Educ. Philos. Theory 2010, 42, 588-605. [CrossRef]

48. Schudel, I.J. Modelling Dialectical Processes in Environmental Learning: An Elaboration of Roy Bhaskar's Onto-axiological Chain. J. Crit. Realis. 2017, 16, 163-183. [CrossRef]

49. Bhaskar, R. Dialectic: The Pulse of Freedom; Verso: London, UK; New York, NY, USA, 1993.

50. Heidegger, M. Sein und zeit, 1967th ed.; Max Niewmeyer Verlag: Tübingen, Germany, 1927.

51. Bhaskar, R. A Realist Theory of Science; Leeds Books: Leeds, UK, 1975.

52. Morton, T. Dark Ecology: For a Logic of Future Coexistence; Columbia University Press: New York, NY, USA, 2016.

53. Bryant, L.R. Objects, Endo-Relational Structures, and Topology. Available online: https://larvalsubjects. wordpress.com/2010/02/25/objects-endo-relational-structures-and-topology/ (accessed on 12 June 2019).

54. Pesanayi, T. Exploring contradictions and absences in mobilizing 'learning as process' for sustainable agricultural practices. In Critical Realism, Environmental Learning and Social-Ecological Change; Price, L., Lotz-Sisitka, H., Eds.; Routledge: London, UK, 2016; pp. 230-253.

55. Mukute, M. Dialectical Critical Realism and Cultural Historical Activity Theory (CHAT): exploring and expanding learning processes in sustainable agriculture workplace contexts. In Critical Realism, Environmental Learning and Social-Ecological Change; Price, L., Lotz-Sisitka, H., Eds.; Routledge: London, UK, 2016; pp. 190-211.

56. Mignolo, W.D. The Intervention of the Human and the Three Pillars of the Colonial Matrix of Power. In On Decoloniality: Concepts, Analytics, Praxis; Mignolo, W.D., Walsh, C.E., Eds.; Duke University Press: Durham, UK, 2018.

57. Geels, F.W. Ontologies, socio-technical transitions (to sustainability), and the multi-level perspective. Res. Policy 2010, 39, 495-510. [CrossRef]

(C) 2019 by the author. Licensee MDPI, Basel, Switzerland. This article is an open access article distributed under the terms and conditions of the Creative Commons Attribution (CC BY) license (http://creativecommons.org/licenses/by/4.0/). 